\title{
Ivabradine does not Impair Anxiety-Like Behavior and Memory in Both Healthy and L-NAME-Induced Hypertensive Rats
}

\author{
K. KRAJCIROVICOVA ${ }^{1}$, S. AZIRIOVA ${ }^{1}$, T. BAKA ${ }^{1}$, K. REPOVA ${ }^{1}$, M. ADAMCOVA ${ }^{2}$, \\ L. PAULIS ${ }^{1,3}$, F. SIMKO ${ }^{1,4,5}$
}

${ }^{1}$ Institute of Pathophysiology, Faculty of Medicine, Comenius University, Bratislava, Slovak Republic, ${ }^{2}$ Department of Physiology, Faculty of Medicine, Charles University, Hradec Kralove, Czech Republic, ${ }^{3}$ Institute of Normal and Pathological Physiology, Center for Experimental Medicine, Slovak Academy of Sciences, Bratislava, Slovak Republic, ${ }^{4}$ Third Department of Internal Medicine, Faculty of Medicine, Comenius University, Bratislava, Slovak Republic, ${ }^{5}$ Institute of Experimental Endocrinology, Biomedical Research Center, Slovak Academy of Sciences, Bratislava, Slovak Republic

Received March 22, 2018

Accepted September 12, 2018

\begin{abstract}
Summary
Cardiovascular pathologies are frequently associated with anxiety and other behavioral disturbances. Ivabradine, an inhibitor of the hyperpolarization-activated cyclic nucleotide-gated channels in the sinoatrial node, decreases heart rate and provides cardiovascular protection. Although ivabradine is increasingly used in cardiovascular medicine, the data on its behavioral effects are lacking. The aim of this work was to show ivabradine's potential effect on behavior in healthy and hypertensive rats. After a four-week treatment period, systolic blood pressure was increased in the $\mathrm{N}(\mathrm{G})$-nitro-L-arginine methyl ester (L-NAME)-group and ivabradine significantly reduced it. Furthermore, it reduced the heart rate in both the control and L-NAME-group. In the control group, ivabradine enhanced the time spent in and transition to the open arms of the elevated plus maze test (EPM). In the L-NAME-group, ivabradine does not show a significant effect on the time spent in the EPM open arms and the number of transitions into them. Furthermore, ivabradine has no impact on cognitive function in both control and L-NAME groups. We conclude that ivabradine showed no undesirable effects on anxiety, locomotion or learning; in fact, some of these parameters were even improved. For the first time it has been shown that ivabradine is a safe cardiovascular drug regarding its effect on psycho-behavioral manifestations.
\end{abstract}

\section{Key words}

Ivabradine • L-NAME • Hypertension • Heart rate • Behavior

\section{Corresponding author}

F. Simko, Institute of Pathophysiology, Faculty of Medicine, Comenius University, Sasinkova 4, 81108 Bratislava, Slovak Republic. Fax: +421-(0)2-59357601. E-mail: fedor.simko@fmed.uniba.sk

\section{Introduction}

Cardiovascular diseases are closely linked to psychological alterations and behavioral disturbances. The relation between cardiac diseases and mental disorders seems to be of a bivalent nature. Hemodynamic disorders associated with neurohumoral imbalance may induce autonomic system changes and psychoemotional alterations; on the other hand, psychosocial stressors, anxiety and conflict situations may be a triggering factor for different cardiovascular pathologies. Thus, anxiety and hypertension are considered to be mutually interdependent entities (Aziriova et al. 2014, Aziriova et al. 2016, Malyszczak and Rymaszewska 2016).

Elevated heart rate (HR) is a neglected risk factor of cardiovascular morbidity and mortality in various cardiovascular pathologies and even among the healthy population (Palatini et al. 2016, Simko et al. 2016, Javorka et al. 2017, Baka and Simko 2018). Treatment by beta-blockers is beneficial for heart failure (HF) or ischemic heart disease, predominantly due to its 
bradycardic and sympatholytic effects (Ponikowski et al. 2016), whereas in hypertension with tachycardia the effect of HR reduction did not bring obvious benefits (Simko and Adamcova 2018). It has been suggested that HR is a mediator of vascular effects induced by chronic stress (Tonhajzerova and Mestanik 2017). Chronic stress impairs endothelial function (Puzserova and Bernatova 2016) and accelerates ischemic brain damage in mice. HR reduction protects against cerebral ischemia by improving endothelial function and reducing the oxidative burden (Custodis et al. 2011). Ivabradine, a new drug acting via a hyperpolarization-activated cyclic nucleotide-gated channel blockade with selective inhibition of $I_{f}$ channel in the sinoatrial node reducing spontaneous pacemaker activity, showed benefits on morbidity and mortality in HF patients (Swedberg et al. 2010). Moreover, its pleiotropic effect on the vasculature, heart and kidneys (Navaratnarajah et al. 2013, Kleinbongard et al. 2015, Simko et al. 2015) may bring benefits in several off-labelled indications (Oliphant et al. 2016), such as hypertensive heart disease. Ivabradine does not interfere with the sympathetic nervous system, thus avoiding the negative inotropic effect of betablockers (Camici et al. 2016). Therefore, it appears to be a promising drug for investigating the impact of pure HR modification on cardiovascular events (Kang et al. 2017). These attributes of ivabradine could be considered as a hopeful therapeutic strategy for hypertensive patients with elevated HR (Palatini et al. 2016).

Although ivabradine is increasingly used in cardiovascular medicine, the data on its behavioral effects are completely lacking. The aim of our work was to show potential ivabradine-induced behavior modifications in healthy rats and rats with hypertension induced by the chronic administration of $\mathrm{N}(\mathrm{G})$-nitro-L-arginine methyl ester (L-NAME).

\section{Material and methods}

\section{Animals and treatment}

Adult (12-week-old) male Wistar rats were randomly divided into four groups ( $\mathrm{n}=10$ per group): controls (ctrl), rats treated with ivabradine (Procoralan $\AA$, Servier, $10 \mathrm{mg} / \mathrm{kg} / 24 \mathrm{~h}$, Iva), L-NAME (Sigma Chemical Co., $40 \mathrm{mg} / \mathrm{kg} / 24 \mathrm{~h}, \mathrm{LN})$, and L-NAME plus ivabradine in corresponding doses (LN+Iva). The substances were administered per os in tap water for the four weeks of the experiment.

Animals were housed in individual cages with a controlled environment of $12 \mathrm{~h} / 12 \mathrm{~h}$ light/dark rhythm, 150 lux light intensity, $21 \pm 2{ }^{\circ} \mathrm{C}$ temperature, $55 \pm 10 \%$ humidity and fed with a regular pellet diet ad libitum. The investigation complied with the Guide for the Care and Use of Laboratory Animals published by US National Institutes of Health (NIH Publication No. 8523, revised 1985). The experiment was approved by the ethical committee of the Institute of Pathophysiology, Faculty of Medicine, Comenius University, Bratislava, Slovak Republic and the State Veterinary Authority of the Slovak Republic (approval number: 1306/14-221).

Systolic blood pressure (SBP) and HR were measured by non-invasive tail-cuff plethysmography after 4 weeks of treatment. During the measurements, the animals were placed in a tunnel-like box, and showed no signs of stress.

Behavioral tests were conducted after four weeks of treatment before euthanasia by decapitation. Behavioral testing was performed during two days. On the first day the open field (OF), elevated-plus maze (EPM) and light-dark box (LDB) tests were accomplished, and after $24 \mathrm{~h}$ the novel object recognition (NOR) tests were performed. During the days of behavioral testing the animals were not exposed to SBP and HR measurements. Behavioral testing was performed during the light period of day (between 6 a.m. 6 p.m.).

\section{Behavioral testing}

Anxiety-like behavior was assessed through the use of a battery of different tests in the following order: OF, EPM and LDB. Memory was evaluated by the NOR test (Holajova and Franek 2018). The animals were tested in the fourth week of treatment. Behavioral analysis was performed using Ethovision XT 10 tracking software (Noldus, Wageningen, Netherlands).

The OF apparatus consisted of a $1 \times 1 \mathrm{~m}$ square located in a dimly lit room. The OF arena was illuminated by a 50 lux light attached on one side and virtually divided into a central part $(50 \times 50 \mathrm{~cm})$ and a border zone. The starting zone was the central part of the OF, and each animal was allowed to explore the arena for 5 min. The time spent in the central part (when the animal had all four paws in the zone) was assessed as a parameter of anti-anxiety behavior. After each animal was measured, the arena was cleaned with $60 \%$ ethanol to remove olfactory cues.

The EPM testing was performed in an apparatus with four arms (elevated $0.5 \mathrm{~m}$ above floor). Two of the arms were open and two were closed by walls 
(0.3 $\mathrm{m}$ high). The EPM was positioned in a dimly lit room, the light intensity was about 50 lux in the open arms and 0 lux in the closed arms. The rats were placed in the central junction and observed for $5 \mathrm{~min}$. The time spent in the open arms was assessed as a parameter of anti-anxiety behavior. A rat was considered to be in the open arm only if all four paws were in the open arm of the maze. In addition, the number of entries to particular arms was recorded. After each animal was measured, the apparatus was cleaned with $60 \%$ ethanol to remove olfactory cues.

The LDB test was performed in an apparatus $(0.3 \times 0.5 \mathrm{~m})$ divided into two parts. The light part was illuminated (50 lux) and the dark part was closed with a lid (0 lux). The rats were placed in the light area and observed for $5 \mathrm{~min}$. The time spent in the light area was assessed as a parameter of anti-anxiety behavior (Racek et al. 2018). After each animal was measured, the apparatus was cleaned with $60 \%$ ethanol to remove olfactory cues.

The NOR test was performed as described previously (Havranek et al. 2015). The OF test was considered a habituation to the apparatus. Thus, NOR tests were performed $24 \mathrm{~h}$ after OF test. The NOR test consisted of a sample trial (T1) and a test trial (T2), each of which had a 5 min duration, separated by a 1-hour retention interval. During $\mathrm{T} 1$, the animals were confronted with two objects (a plastic bottle and a metallic bottle) placed diagonally across from each other in the corners of the arena. The time spent exploring object 1 (the plastic bottle) and 2 (the metallic bottle) was marked a1 and a2, respectively. During T2, one object (the plastic bottle) was left (time a3) and the other bottle was replaced by a novel object (a glass bottle, time b). Before each trial, the objects and platform were cleaned with $60 \%$ ethanol to remove olfactory cues. During the trial, the animals could freely explore the arena and objects, and the time spent interacting with each individual object during $\mathrm{T} 1$ and $\mathrm{T} 2$ was recorded and analyzed. Several variables were calculated based on the time spent exploring each object. The values e1 and e2 are measures of the total time spent investigating both objects during $\mathrm{T} 1$ and $\mathrm{T} 2(\mathrm{e} 1=\mathrm{a} 1+\mathrm{a} 2 ; \mathrm{e} 2=\mathrm{a} 3+\mathrm{b})$. The $\mathrm{d} 1$ index measures the absolute difference between the sample and the novel object $(\mathrm{d} 1=\mathrm{b}-\mathrm{a} 3)$. The $\mathrm{d} 2$ index is a relative measure of discrimination corrected for the level of exploration in the test trial $(\mathrm{e} 2 ; \mathrm{d} 2=\mathrm{d} 1 / \mathrm{e} 2)$ and the $\mathrm{d} 3$ index shows the proportion of e 2 devoted to the novel object $(\mathrm{d} 3=\mathrm{b} / \mathrm{e} 2)$. All parameters were calculated as previously described (Akkerman et al. 2012).

\section{Statistical analysis}

The results are expressed as mean \pm S.E.M. Differences were significant if the $p$-value was less than 0.05. The Shapiro-Wilk test was used to detect whether the data were distributed normally. All data were normally distributed. A one-way analysis of variance (ANOVA) with a LSD post hoc test was used in the normally distributed data for statistical analysis purposes. The Pearson correlation was used to indicate the relationship between SBP and HR with parameters of anxiety-like behavior and memory in normally distributed data.

\section{Results}

\section{Hemodynamic parameters after four weeks of treatment}

Systolic blood pressure was $123.6 \pm 2.1 \mathrm{~mm} \mathrm{Hg}$ in the control group after four weeks of treatment and increased in the LN-group (by $47.8 \%, p<0.05$ ). Ivabradine had no effect on SBP in the controls but SBP was reduced by ivabradine in the LN-group (by $14.8 \%$, $p<0.05$ ) (Fig. 1A).
A

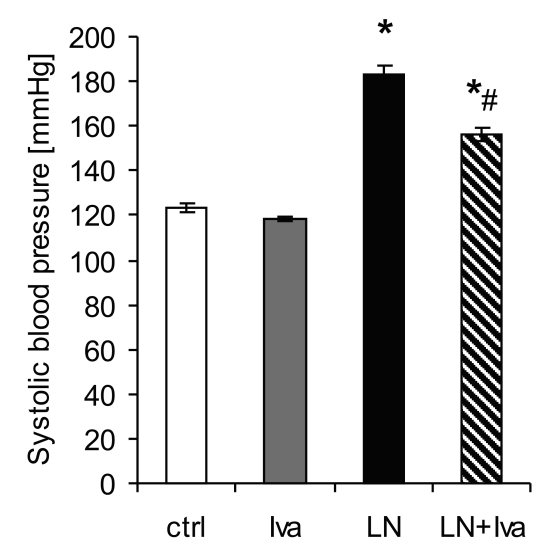

B

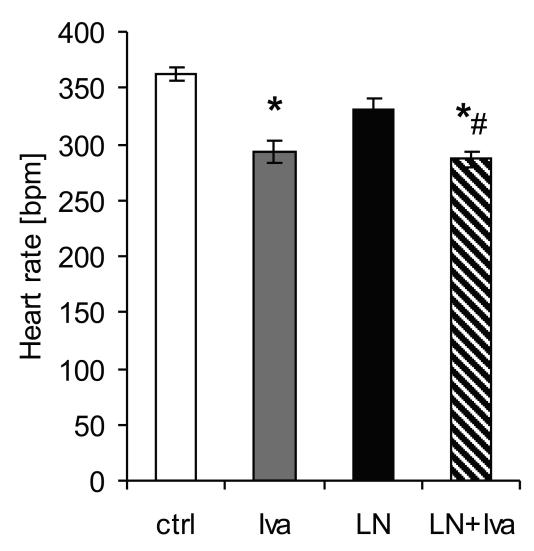

Fig. 1. Systolic blood pressure (SBP) (A) and heart rate (B) after four weeks of treatment. The effect of ivabradine on SBP and heart rate in controls (Iva) and L-NAME-induced hypertension (LN+Iva). ctrl, control; Iva, ivabradine; LN, L-NAME; * $p<0.05$ vs. ctrl, ${ }^{\#} p<0.05$ vs. LN. 
Heart rate was $357.2 \pm 4.5 \mathrm{bpm}$ in the control group after four weeks of treatment and remained unchanged in the LN-group. Ivabradine decreased HR in the control group as well as in the LN-group (by $19.3 \%$, $p<0.05$, and $13.3 \%, p<0.05$, respectively) (Fig. 1B).

\section{Open field test}

Locomotion in the control group was $1,863.9 \pm 100.9 \mathrm{~cm}$ after four weeks of treatment and L-NAME administration had no effect. Ivabradine showed a trend to decrease the locomotor activity in the control group (by $15.7 \%$, ns) but had no effect in LN-group. Rearing activity in the control group was $55.3 \pm 3.6 \mathrm{~s}$ after four weeks of treatment, while L-NAME had no effect. Ivabradine decreased rearing activity in the control group (by $22.6 \%, p<0.05$ ) but not in LN-group.

In the control group, the time spent in the central square of the OF was $15.9 \pm 3.0 \mathrm{~s}$ after four weeks of treatment; L-NAME had no effect. Ivabradine showed a trend to the increase of the time spent in the central square of the OF in the control group (by $16.4 \%$, ns), but had no effect in the LN-group. There were no differences between groups in average speed and zone transitions in the OF.

\section{Elevated-plus maze test}

In the control group, the percentage of time spent in the open arms of the EPM was $15.8 \pm 4.3 \%$; and there was a trend to increase in the LN-group (by $81.9 \%$, ns). Ivabradine increased the percentage of time spent in the open arms of the EPM in the control group (by $100.7 \%, p<0.05$ ), and showed a trend to decrease it in the LN-group (by $32.5 \%$, ns) (Fig. 2A).
A

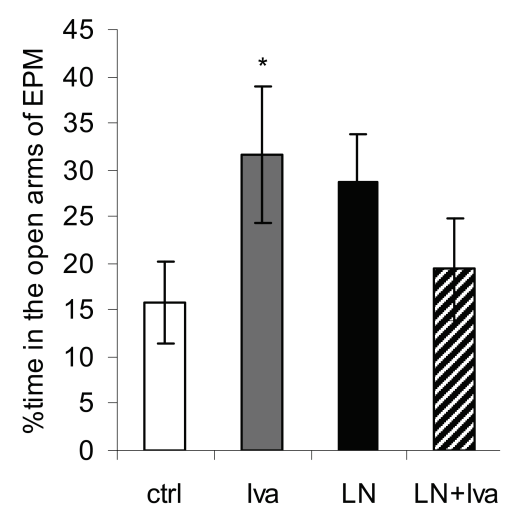

C

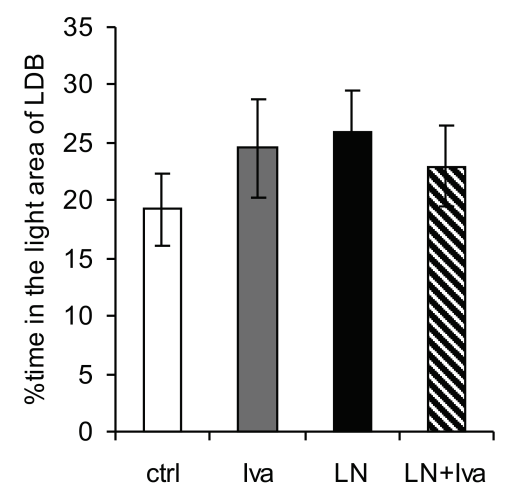

B

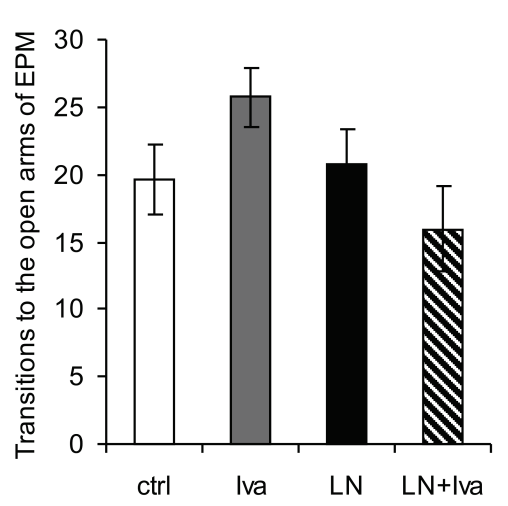

D

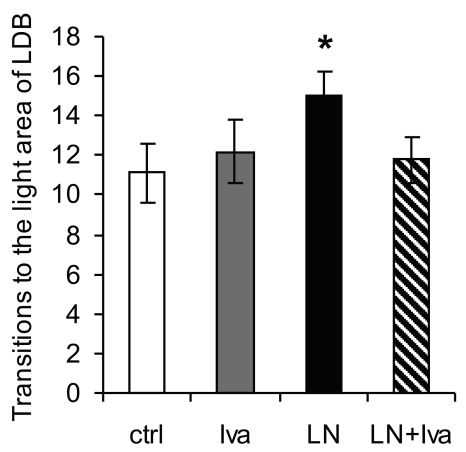

Fig. 2. Percentage of time spent in the open arms of the elevated plus maze (EPM) (A), number of transitions to the open arms of the EPM (B), percentage of time spent in the light area of the light-dark box (LDB) (C) and number of transitions to the light area of the LDB (D). The effect of ivabradine on anxiety-like behaviour in controls (Iva) and L-NAME-induced hypertension (LN+Iva). ctrl, control; Iva, ivabradine; LN, L-NAME; $* p<0.05$ vs. ctrl.
The number of transitions to the open arms of the EPM was $19.7 \pm 2.6$ in the control group and was not affected by L-NAME. Ivabradine had no influence on the number of transitions in the control group, while L-NAME slightly decreased them (by $23.4 \%, p<0.05$ ) (Fig. 2B).

There were no differences between groups in average speed in the EPM.

\section{Light-dark box test}

In the control group, the percentage of time spent in the light area of the LDB was $19.2 \pm 3.1 \%$; and showed a trend to increase in the LN-group (by $34.3 \%$, ns). Ivabradine did not change the percentage of time 
spent in the light area of the LDB in the control group or in the LN-group (Fig. 2C).

The number of transitions to the light area of the LDB was $11.1 \pm 1.5$ in the control group while L-NAME increased the number of transitions (by $36.4 \%, p<0.05$ ). Ivabradine did not change the number of transitions in the control group or the LN-group (Fig. 2D).

There were no differences between groups in average speed in the LDB.

\section{Novel object recognition test}

During first object-exposure, there were no differences between groups in total exploratory activity (e1) (Fig. 3A). In the second trial, after one-hour retention, a slightly higher preference for the new object (d1) was observed in the Iva-group (by $60.0 \%$, ns)
(Fig. 3B). The relative level of discrimination corrected for total activity (d2) was slightly increased in the Iva-group (by $72.7 \%$, ns) (Fig. 3C). The proportion of time devoted to the novel object compared to the time spent investigating both objects (d3) showed no change (Fig. 3D).

Correlations between systolic blood pressure or heart rate with behavioral parameters in groups with ivabradine

In the Iva group, there was a strong negative correlation between SBP after four weeks of treatment and the time spent in the light area in LDB $(r=-0.923$, $p=0.000$ ) (Fig. 4A). There were no other correlations between SBP or HR and other parameters of the behavior in the Iva group (Fig. 4B-4H).
A

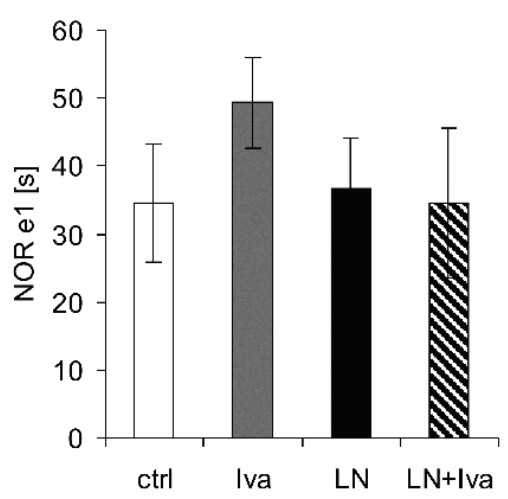

C

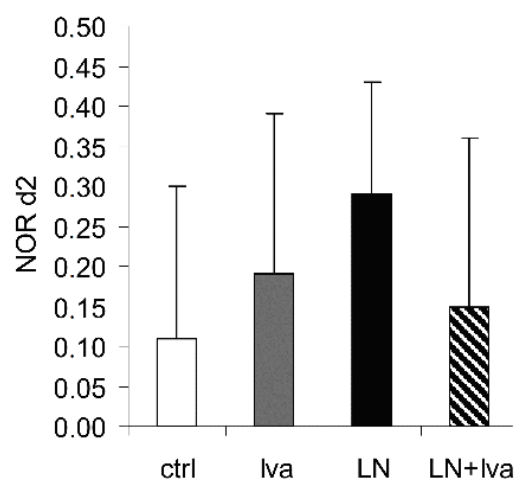

B

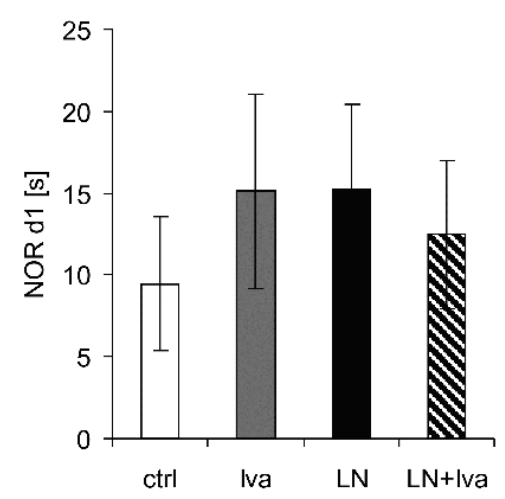

D

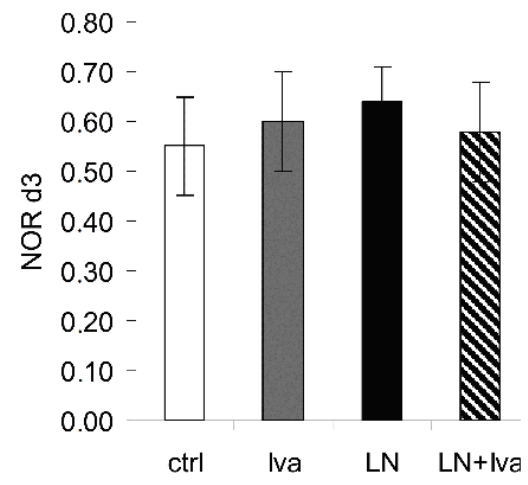

Fig. 3. Total exploratory activity in the first test trial (e1) (A), exploration of novel object $(\mathrm{d} 1)(\mathbf{B})$, relative level of discrimination corrected for the total activity (d2) (C) and proportion of time devoted to the novel object to the time spent investigating both objects (d3) (D) in the novel object recognition (NOR) test. The effect of ivabradine on memory in controls (Iva) and L-NAME-induced hypertension (LN+Iva). ctrl, control; Iva, ivabradine; LN, L-NAME.

\section{Discussion}

Virtually every cardiovascular pathology manifested by hemodynamic and metabolic changes may be related to concomitant psychological or psychiatric disturbances. The cardiovascular disease itself and its negative psychological impact may result in sadness, anxiety, chronic stress or depression (Ivanovs et al. 2018, Trebatická et al. 2017). On the other hand, cardiovascular drugs may either alleviate or exacerbate these psychological and behavioral alterations. It is of utmost importance to know the potential pro- or antidepressant or anxiolytic nature of pharmacological substances. 
A

Correlation between SBP and

LDB light area time in ivabradine group

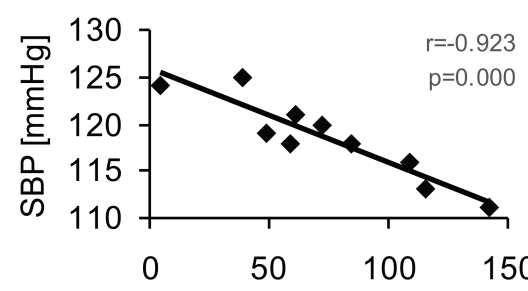

LDB time in the light area [s]

C

Correlation between SBP and OF center time in ivabradine group

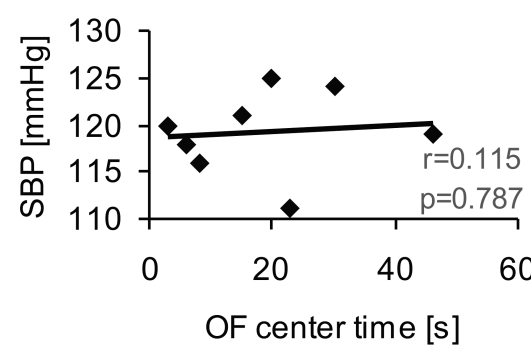

E

Correlation between HR and

LDB time in the light area in ivabradine group

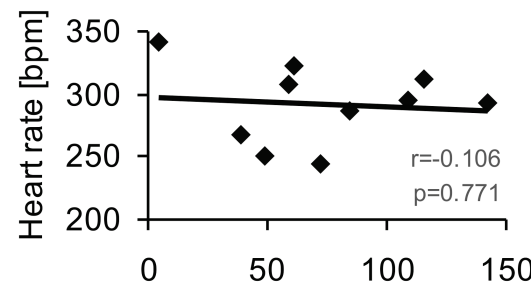

LDB time in the light area [s]

G

Correlation between HR and OF center time in ivabradine group

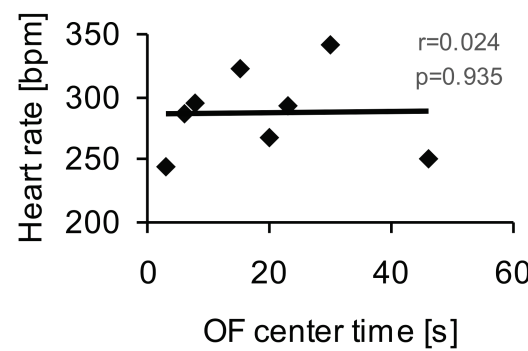

B

Correlation between SBP and EPM time in the open arms in ivabradine group

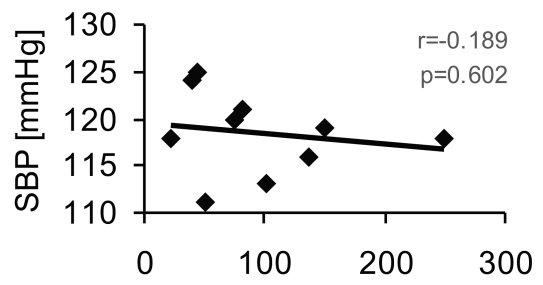

EPM time in the open arms [s]

D

Correlation between SBP and NOR d1 in ivabradine group

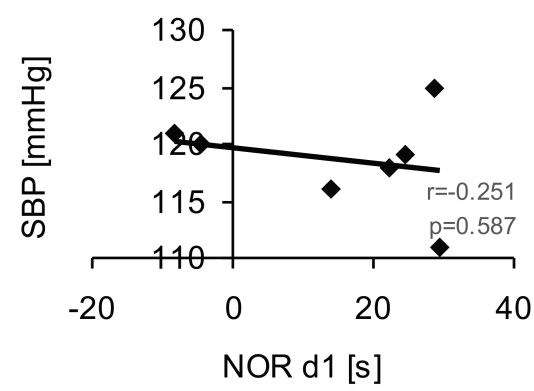

$\mathrm{F}$

Correlation between HR and EPM time in the open arms in ivabradine group

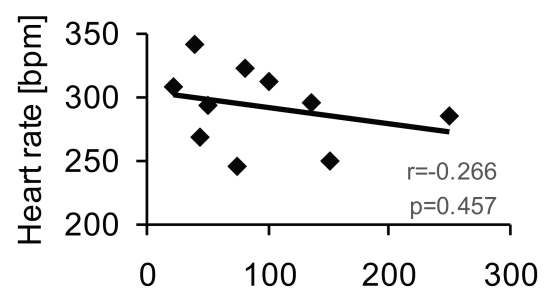

EPM time in the open arms [s]

$\mathrm{H}$

Correlation between HR and NOR d1 in ivabradine group

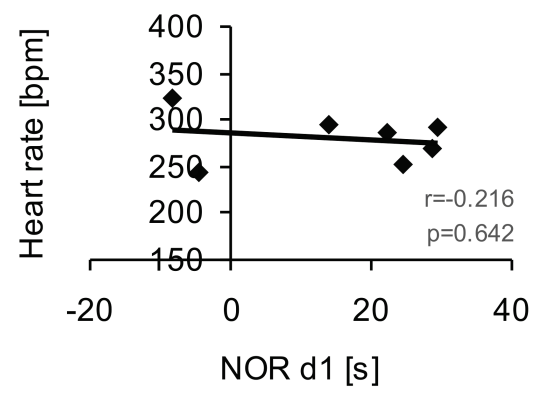

Fig. 4. Correlations between systolic blood pressure (SBP) and heart rate (HR) after four weeks of treatment with parameters of anxiety-like behaviour $(\mathbf{A}, \mathbf{B}, \mathbf{C}, \mathbf{E}, \mathbf{F}, \mathbf{G})$ and memory $(\mathbf{D}, \mathbf{H})$ in ivabradine group. $r$, Pearson correlation coefficient; $p, p$-value; LDB, light-dark box; EPM, elevated plus maze; OF, open field; NOR d1, exploration of novel object in the novel object recognition test. 
Although the possible behavioral effects of angiotensin, aldosterone and their inhibition by variable substrates are generally known (Hlavacova et al. 2010, Krskova et al. 2009), the data on the ivabradine's behavioral manifestations are completely lacking. To date, only the work by our group regarding the effect of ivabradine on food and water intake, body weight gain, and exploratory activity has been published (Aziriova et al. 2016).

This experiment demonstrated that in the control group ivabradine enhanced the time spent in the open arms of the EPM and showed a trend to increase the number of transitions into the open arms. In addition, it did not show a negative impact on the cognitive function. Determining the effect of ivabradine or any other cardiovascular drug in non-diseased individuals is of utmost importance, since a discernible number of patients have false diagnoses and their inappropriate placement in long-course therapy may potentially induce iatrogenic psychological alterations. It seems that ivabradine has no adverse effects and might even have anxiolytic effects on behavior.

The model of L-NAME-induced hypertension has been chosen for testing the ivabradine's effects from several reasons. First, in general, this is one of the best established models of experimental hypertension with proven end-stage organ damage. The situation in the L-NAME model is complex. L-NAME is a non-specific inhibitor of nitric oxide synthase resulting in endothelial dysfunction with decreased NO production in various organs including the brain (Bernatova et al. 1999), hypertension development, and fibrotic remodeling of the left ventricle, kidney, or aorta (Pechanova et al. 1997, Bernatova et al. 2000, Simko et al. 2004, Simko et al. 2005, Bernatova et al. 2016, Simko et al. 2017). Especially the prominent proteosynthetic and proliferative effects of L-NAME administration in the brain, reflected by increased concentrations of ribonucleic and deoxyribonucleic acids in the brain tissue (Bernatova et al. 1999), suggest the potential of behavioral changes in this model. Second, in addition to hemodynamic changes, prominent neurohumoral alterations (Simko and Simko 2000, Sestakova et al. 2013, Riljak et al. 2016) as a result of endothelial dysfunction-induced vasoconstriction of the renal artery and concomitant renin-angiotensin-aldosterone system activation, may contribute to structural and functional changes of organs and potential behavioral alterations; whereas aldosterone seems to play an important or even dominant role (Simko et al. 2018). Third, we have quite a large experience with the testing of the potential protective effect of various drugs on the cardiovascular system in the L-NAMEmodel, such as captopril (Pechanova et al. 1997, Bernatova 2000), spironolactone (Simko et al. 2007), L-arginine (Simko et al. 2005), simvastatin (Simko et al. 2004) and melatonin (Paulis et al. 2009, Paulis et al. 2010, Simko et al. 2010). Thus the comparison of the acquired results is possible. On the other hand, the complexity of the pathophysiological background of this model may be due to the fact that the data regarding psychoemotional manifestation vary significantly - from anxiogenic-like effects (Vale et al. 1998, Czech et al. 2003, Zarrindast et al. 2011) to anxiolytic and antidepressant actions (Guimaraes et al. 1994, Deep et al. 2016). These differences in behavioral manifestations observed in various laboratories may be related to the various dose of L-NAME (ranging from 10 to $60 \mathrm{mg} / \mathrm{kg}$ ), different period of L-NAME application or different rat age and strain used. In our experiment, four-week L-NAME $(40 \mathrm{mg} / \mathrm{kg})$ administration has no effect on behavior and ivabradine did not deteriorate the behavioral parameters in comparison to the control or L-NAME group in any test.

We have investigated the potential correlations between SBP and HR on the one hand and EPM, LDB, and NOR parameters on the other one in the Iva group (Fig. 4). No correlations between hemodynamic and behavioral parameters were detected. The only exception was a significant correlation between SBP and LDB light area time (Fig. 4A), however there was no significant change between the control and ivabradine group in this parameter. Altogether, these data seem to indicate that behavioral changes are not related to SBP or HR alterations and might be more tightly bound to the pleiotropic action of ivabradine (on endothelium, mitochondrial metabolism or oxidative stress) or to neurohumoral alterations in the L-arginine-NO cascade or renin-angiotensin-aldosterone system.

This neutral effect of ivabradine on behavior may be of significant clinical benefit. In a number of clinical situations with increased heart rate, beta-blocker inhibiting the receptor-mediated tachycardic effect of the sympathetic nervous system has been the drug of choice. However, the potentially desirable bradycardic and blood pressure reducing effects of beta-blockers may be counterbalanced by their negative metabolic actions (like hyperuricemia and dysliporoteinemia). Moreover, treatment with beta-blockers seems to reduce the 
nocturnal melatonin secretion through the blockade of $\beta 1$-receptors in the central nervous system related to sleep disturbances and nightmares (Brismar et al. 1987, Gleiter et al. 1996). In patients with the need of HR reduction, ivabradine, which seems to be metabolically inert and not inducing psychical disturbances, could make it possible to replace beta-blockers or at least to reduce their dose by concomitant treatment.

In conclusion, it was shown for the first time that ivabradine seems to be a safe cardiovascular drug regarding its effect on psycho-behavioral manifestations.

\section{Conflict of Interest}

There is no conflict of interest.

\section{Acknowledgements}

This work was supported by grants for scientific research: VEGA 1/0071/15; VEGA 2/0195/15; UK/96/2015; and Programme PROGRES Q40/5.

\section{References}

AKKERMAN S, PRICKAERTS J, STEINBUSCH HW, BLOKLAND A: Object recognition testing: statistical considerations. Behav Brain Res 232: 317-322, 2012.

AZIRIOVA S, REPOVA BEDNAROVA K, KRAJCIROVICOVA K, HRENAK J, RAJKOVICOVA R, ARENDASOVA K, KAMODYOVA N, CELEC P, ZORAD S, ADAMCOVA M, PAULIS L, SIMKO F: Doxorubicin-induced behavioral disturbances in rats: protective effect of melatonin and captopril. Pharmacol Biochem Behav 124: 284-289, 2014.

AZIRIOVA S, REPOVA K, KRAJCIROVICOVA K, BAKA T, ZORAD S, MOJTO V, SLAVKOVSKY P, HODOSY J, ADAMCOVA M, PAULIS L, SIMKO F: Effect of ivabradine, captopril and melatonin on the behaviour of rats in L-nitro-arginine methyl ester-induced hypertension. J Physiol Pharmacol 67: 895-902, 2016.

BAKA T, SIMKO F: Nondipping heart rate: A neglected cardiovascular risk factor based on autonomic imbalance? Auton Neurosci 210: 83-84, 2018.

BERNATOVA I, PECHANOVA O, SIMKO F: Effect of captopril in L-NAME-induced hypertension on the rat myocardium, aorta, brain and kidney. Exp Physiol 84: 1095-1105, 1999.

BERNATOVA I, PECHANOVA O, PELOUCH V, SIMKO F: Regression of chronic L-NAME-treatment-induced left ventricular hypertrophy: effect of captopril. J Mol Cell Cardiol 32: 177-185, 2000.

BERNATOVA I, BALIS P, GOGA R, BEHULIAK M, ZICHA J, SEKAJ I: Lack of reactive oxygen species deteriorates blood pressure regulation in acute stress. Physiol Res 65 (Suppl 3): S381-S390, 2016.

BRISMAR K, MOGENSEN L, WETTERBERG L: Depressed melatonin secretion in patients with nightmares due to beta-adrenoceptor blocking drugs. Acta Med Scand 221: 155-158, 1987.

CAMICI PG, GLOEKLER S, LEVY BI, SKALIDIS E, TAGLIAMONTE E, VARDAS P, HEUSH G: Ivabradine in chronic stable angina: Effects by and beyond heart rate reduction. Int J Cardiol 215: 1-6, 2016.

CZECH DA, JACOBSON EB, LESUEUR-REED KT, KAZEL MR: Putative anxiety-linked effects of the nitric oxide synthase inhibitor L-NAME in three murine exploratory behavior models. Pharmacol Biochem Behav 75 : 741-748, 2003.

CUSTODIS F, GERTZ K, BALKAYA M, PRINZ V, MATHAR I, STAMM C, KRONENBERG G, KAZAKOV A, FREICHEL M, BÖHM M, ENDRES M, LAUFS U: Heart rate contributes to the vascular effects of chronic mental stress: effects on endothelial function and ischemic brain injury in mice. Stroke 42: 1742-1749, 2011.

DEEP SN, BAITHARU I, SHARMA A, GURJAR AK, PRASAD D, SINGH SB: Neuroprotective role of L-NGnitroarginine methyl ester (L-NAME) against chronic hypobaric hypoxia with crowding stress (CHC) induced depression-like behaviour. PLoS One 15: e0153371, 2016.

GLEITER CH, DECKERT J: Adverse CNS-effects of beta-adrenoceptor blockers. Pharmacopsychiatry 29: 201-211, 1996.

GUIMARÃES FS, DE AGUIAR JC, DEL BEL EA, BALLEJO G: Anxiolytic effect of nitric oxide synthase inhibitors microinjected into the dorsal central grey. Neuroreport 3: 1929-1932, 1994. 
HAVRANEK T, ZATKOVA M, LESTANOVA Z, MRAVEC B, HODOSY J, STRBAK V, BAKOS J: Intracerebroventricular oxytocin administration in rats enhances object recognition and increases expression of neurotrophins, microtubule-associated protein 2, and synapsin I. J Neurosci Res 93: 893-901, 2015.

HLAVACOVA N, BAKOS J, JEZOVA D: Eplerenone, a selective mineralocorticoid receptor blocker, exerts anxiolytic effects accompanied by changes in stress hormone release. J Psychopharmacol 24: 779-786, 2010.

HOLAJOVA M, FRANEK M: Effect of short- and long-term administration of baclofen on spatial learning and memory in rats. Physiol Res 67: 133-141, 2018.

IVANOVS R, KIVITE A, ZEIDONIS D, MINTALE I, VRUBLEVSKA J, RANCANS E: Association of depression and anxiety with cardiovascular co-morbidity in a primary cera population in Litvia: a cross-sectional study. BMC Public Health 18: 328, 2018.

JAVORKA K, LEHOTSKA Z, KOZAR M, UHRIKOVA Z, KOLAROVSZKI B, JAVORKA M, ZIBOLEN M: Heart rate variability in newborns. Physiol Res 66 (Suppl 2): S203-S214, 2017.

KANG S, LI CJ, ZHANG XM: Ivabradine has a neutral effect on mortality in randomized controlled trials. Medicine (Baltimore) 96: E8067, 2017.

KLEINBONGARD P, GEDIK N, WITTING P, FREEDMAN B, KLOCKER N, HEUSCH G: Pleiotropic, heart rateindependent cardioprotection by ivabradine. Br J Pharmacol 172: 4380-4390, 2015.

KRSKOVA L, VRABCOVA M, TALAROVICOVA A, ZEMAN M: Influence of up-regulated renin-angiotensin system on the exploration, anxiety-related behavior and object recognition. Acta Biol Hung 60: 369-383, 2009.

MALYSZCZAK KM, RYMASZEWSKA J: Depression and anxiety incardiovascular disease. Kardiol Pol 74: 603-609, 2016.

NAVARATNARAJAH M, IBRAHIM M, SIEDLECKA U, VAN DOORN C, SHAH A, GANDHI A, DIAS P, SARATHCHANDRA $\mathrm{P}$, YACOUB MH, TERRACCIANO CM: Influence of ivabradine on reverse remodelling during mechanical unloading. Cardiovasc Res 97: 230-239, 2013.

OLIPHANT CS, OWENS RE, BOLORUNDURO OB, JHA SK: Ivabradine: a review of labeled and off-label uses. Am J Cardiovasc Drugs 16: 337-347, 2016.

PALATINI P, ROSEI EA, CASIGLIA E, CHALMERS J, FERRARI R, GRASSI G, INOUE T, JELAKOVIC B, JENSEN MT, JULIUS S, KJELDSEN SE, MANCIA G, PARATI G, PAULETTO P, STELLA A, ZANCHETTI A: Management of the hypertensive patient with elevated heart rate: Statement of the Second Consensus Conference endorsed by the European Society of Hypertension. J Hypertens 34: 813-821, 2016.

PAULIS L, PECHANOVA O, ZICHA J, KRAJCIROVICOVA K, BARTA A, PELOUCH V, ADAMCOVA M, SIMKO F: Melatonin prevents fibrosis but not hypertrophy development in the left ventricle of NG-nitro-L-arginine-methyl ester hypertensive rats. J Hypertens Suppl 27: S11-S16, 2009.

PAULIS L, PECHANOVA O, ZICHA J, BARTA A, GARDLIK R, CELEC P, KUNES J, SIMKO F: Melatonin interactions with blood pressure and vascular function during L-NAME-induced hypertension. J Pineal Res 48 : 102-108, 2010.

PECHANOVA O, BERNATOVA I, PELOUCH V, SIMKO F: Protein remodelling of the heart in NO-deficient hypertension: the effect of captopril. J Mol Cell Cardiol 29: 3365-3374, 1997.

PONIKOWSKI P, VOORS AA, ANKER SD, BUENO H, CLELAND JGF, COATS AJS, FALK V, GONZÁLEZJUANATEY JR, HARJOLA VP, JANKOWSKA EA, JESSUP M, LINDE C, NIHOYANNOPOULOS P, PARISSIS JT, PIESKE B, RILEY JP, ROSANO GMC, RUILOPE LM, RUSCHITZKA F, RUTTEN FH, VAN DER MEER P; ESC SCIENTIFIC DOCUMENT GROUP: 2016 ESC Guidelines for the diagnosis and treatment of acute and chronic heart failure: The Task Force for the diagnosis and treatment of acute and chronic heart failure of the European Society of Cardiology (ESC). Developed with the special contribution of the Heart Failure Association (HFA) of the ESC. Eur J Heart Fail 18: 891-975, 2016.

PUZSEROVA A, BERNATOVA I: Blood pressure regulation in stress: focus on nitric oxide-dependent mechanisms. Physiol Res 65 (Suppl 3): S309-S342, 2016.

RACEK A, BENOVA K, ARNOUL P, ZAVODSKA M, ANGELIDIS A, CIGANKOVA V, SIMAIOVA V, RACEKOVA E: Age-dependent effect of long-term microwave radiation on postnatal neurogenesis in rats: morphological and behavioral study. Physiol Res 67: 495-503, 2018. 
RILJAK V, KRAF J, DARYANANI A, JIRUŠKA P, OTÁHAL J: Pathophysiology of perinatal hypoxic-ischemic encephalopathy - biomarkers, animal models and treatment perspectives. Physiol Res 65 (Suppl 5): S533-S545, 2016.

SESTAKOVA N, PUZSEROVA A, KLUKNAVSKY M, BERNATOVA I: Determination of motor activity and anxiety-related behaviour in rodents: methodological aspects and role of nitric oxide. Interdiscip Toxicol 6: 125-135, 2013.

SIMKO F, SIMKO J: The potential role of nitric oxide in the hypertrophic growth of the left ventricle. Physiol Res 49: 37-46, 2000.

SIMKO F, MATUSKOVA J, LUPTAK I, KRAJCIROVICOVA K, KUCHARSKA J, GVOZDJAKOVA A, BABAL P, PECHANOVA O: Effect of simvastatin on remodeling of the left ventricle and aorta in L-NAME-induced hypertension. Life Sci 74: 1211-1224, 2004.

SIMKO F, LUPTAK I, MATUSKOVA J, KRAJCIROVICOVA K, SUMBALOVA Z, KUCHARSKA J, GVOZDJAKOVA A, SIMKO J, BABAL P, PECHANOVA O, BERNATOVA I: L-arginine fails to protect against myocardial remodelling in L-NAME-induced hypertension. Eur J Clin Invest 35: 362-368, 2005.

SIMKO F, MATÚSKOVÁ J, LUPTÁK I, PINCÍKOVÁ T, KRAJCÍROVICOVÁ K, STVRTINA S, POMSÁR J, PELOUCH V, PAULIS L, PECHÁNOVÁ O: Spironolactone differently influences remodeling of the left ventricle and aorta in L-NAME-induced hypertension. Physiol Res 56 (Suppl 2): S25-S32, 2007.

SIMKO F, PECHANOVA O, PELOUCH V, KRAJCIROVICOVA K, CELEC P, PALFFY R, BEDNAROVA K, VRANKOVA S, ADAMCOVA M, PAULIS L: Continuous light and L-NAME-induced left ventricular remodelling: different protection with melatonin and captopril. J Hypertens 28 (Suppl 1): S13-S18, 2010.

SIMKO F, REPOVA K, KRAJCIROVICOVA K, AZIRIOVA S, PAULIS L, BAKA T: Remodelling of the aorta and kidney in L-NAME-induced hypertension in rats: comparison of the protective effect of ivabradine with captopril and melatonin. Diabetologia 58 (Suppl 1): S547, 2015.

SIMKO F, BAKA T, PAULIS L, REITER RJ: Elevated heart rate and nondipping heart rate as potential targets for melatonin: a review. J Pineal Res 61: 127-137, 2016.

SIMKO F, PECHANOVA O, REPOVA K, AZIRIOVA S, KRAJCIROVICOVA K, CELEC P, TOTHOVA L, VRANKOVA S, BALAZOVA L, ZORAD S, ADAMCOVA M: Lactacystin-induced model of hypertension in rats: effects of melatonin and captopril. Int J Mol Sci 18: pii: E1612, 2017.

SIMKO F, BAKA T, KRAJCIROVICOVA K, REPOVA K, AZIRIOVA S, ZORAD S, POGLITSCH M, ADAMCOVA M, REITER RJ, PAULIS L: Effect of melatonin on the renin-angiotensin-aldosterone system in L-NAME-induced hypertension. Molecules 23: pii: E265, 2018.

SIMKO F, ADAMCOVA M: What prevents cardioprotective drugs from reaching the market? Expert Rev Clin Pharmacol 11: 463-465, 2018.

SWEDBERG K, KOMAJDA M, BÖHM M, BORER JS, FORD I, DUBOST-BRAMA A, LEREBOURS G, TAVAZZI L, SHIFT INVESTIGATORS: Ivabradine and outcomes in chronic heart failure (SHIFT): a randomised placebo-controlled study. Lancet 376: 875-885, 2010.

TONHAJZEROVA I, MESTANIK M: New perspectives in the model of stress response. Physiol Res 66 (Suppl 2): S173-S185, 2017.

TREBATICKÁ J, DUKÁT A, ĎURAČKOVÁ Z, MUCHOVÁ J: Cardiovascular diseases, depression disorders and potential effects of omega-3 fatty acids. Physiol Res 66: 363-382, 2017.

VALE AL, GREEN S, MONTGOMERY AM, SHAFI S: The nitric oxide synthesis inhibitor L-NAME produces anxiogenic-like effects in the rat elevated plus-maze test, but not in the social interaction test. J Psychopharmacol 12: 268-272, 1998.

ZARRINDAST MR, NASEHI M, KHANSARI M, BANANEJ M: Influence of nitric oxide agents in the rat amygdala on anxiogenic-like effect induced by histamine. Neurosci Lett 489: 38-42, 2011. 